\title{
Mechanistic aspects of biosynthesis of silver nanoparticles by several
} Fusarium oxysporum strains

\author{
Nelson Durán*1,2, Priscyla D Marcato ${ }^{\dagger 1}$, Oswaldo L Alves ${ }^{\dagger 3}$, Gabriel IH De \\ Souza $^{\dagger 2}$ and Elisa Esposito ${ }^{\dagger 2}$
}

\begin{abstract}
Address: ${ }^{1}$ Biological Chemistry Laboratory, Instituto de Química, Universidade Estadual de Campinas, CEP 13084862, Caixa Postal 6154, Campinas, S.P., Brazil, ${ }^{2}$ Biological Chemistry and Biotechnology Laboratory, Center Environmental Sciences, Universidade de Mogi das Cruzes, Mogi das Cruzes, S.P., Brazil and ${ }^{3}$ Solid State Chemistry Laboratory, Instituto de Química, Universidade Estadual de Campinas, CEP 13084862, Caixa Postal 6154, Campinas, S.P., Brazil

Email: Nelson Durán* - duran@iqm.unicamp.br; Priscyla D Marcato - priscyla@iqm.unicamp.br; Oswaldo L Alves - oalves@iqm.unicamp.br; Gabriel IH De Souza - gabrinacio@yahoo.com.br; Elisa Esposito - elisa@umc.br

* Corresponding author †Equal contributors
\end{abstract}

Published: 13 July 2005

Journal of Nanobiotechnology 2005, 3:8 doi:10.1186/1477-3155-3-8
Received: II January 2005

Accepted: 13 July 2005

This article is available from: http://www.jnanobiotechnology.com/content/3/1/8

(c) 2005 Durán et al; licensee BioMed Central Ltd.

This is an Open Access article distributed under the terms of the Creative Commons Attribution License (http://creativecommons.org/licenses/by/2.0), which permits unrestricted use, distribution, and reproduction in any medium, provided the original work is properly cited.

\begin{abstract}
Extracellular production of metal nanoparticles by several strains of the fungus Fusarium oxysporum was carried out. It was found that aqueous silver ions when exposed to several Fusarium oxysporum strains are reduced in solution, thereby leading to the formation of silver hydrosol. The silver nanoparticles were in the range of $20-50 \mathrm{~nm}$ in dimensions. The reduction of the metal ions occurs by a nitrate-dependent reductase and a shuttle quinone extracellular process. The potentialities of this nanotechnological design based in fugal biosynthesis of nanoparticles for several technical applications are important, including their high potential as antibacterial material.
\end{abstract}

\section{Background}

The dissimilatory ferric reductase, which are found in bacteria are an essential part of the iron cycles [1] and are essentially intracellular, but one extracellular one was isolated from Mycobacterium paratuberculosis [2]. Another possible mechanism could be active in this process since it was discovered that some bacteria reduce $\mathrm{Fe}^{3+}$ oxides by producing and secreting small, diffusible redox compounds that can serve as electron shuttle between the microbe and the insoluble iron substrate [3]. The role of excreted compounds in extracellular electron transfer was recently reviewed [4].

The presence of hydrogenase in fungus as Fusarium oxysporum was demonstrated with washed cell suspensions that had been grown aerobically and anaerobically in a medium with glucose and salts amended with nitrate [5].
The nitrate reductase was apparently essential for ferric iron reduction [6]. Many fungi that exhibit these characteristic properties, in general, are capable of reducing $\mathrm{Au}$ (III) or Ag (I) [7]. Besides these extracellular enzymes, several naphthoquinones [8-10] and anthraquinones [11] with excellent redox properties, were reported in F. oxysporum that could be act as electron shuttle in metal reductions [3].

Although it is known that microorganisms such as bacteria, yeast and now fungi play an important role in remediation of toxic metals through reduction of the metal ions, this was considered interesting as nanofactories very recently [12]. Using these dissimilatory properties of fungi, the biosynthesis of inorganic nanomaterials using eukaryotic organisms such as fungi may be used to grow nanoparticles of gold [13] and silver [14] intracellularly in 


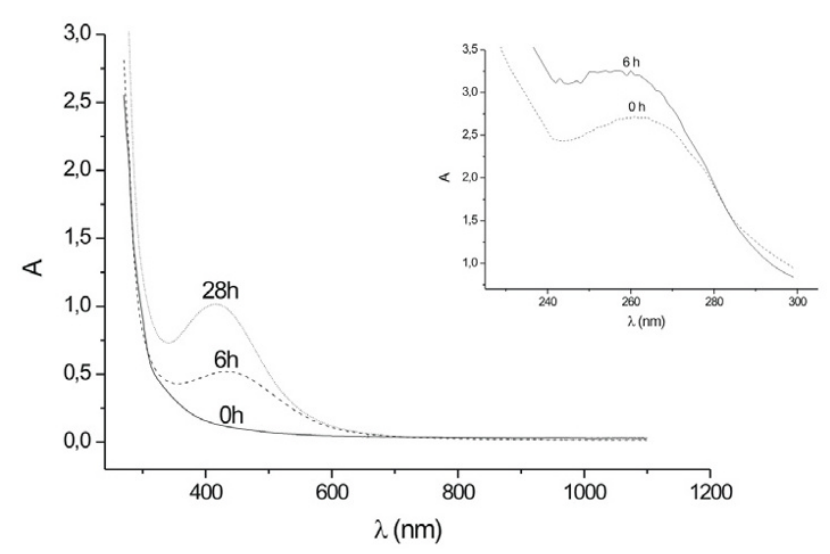

Figure I

UV-Vis spectra recorded as a function of time of reaction of an aqueous solution of $10^{-3} \mathrm{M} \mathrm{AgNO}_{3}$ with the fungal biomass (07SD). The inset shows the UV-Vis absorption in the low wavelength region.

Verticillium fungal cells [15]. Recently, it was found that aqueous chloroaurate ions may be reduced extracellularly using the fungus F. oxysporum, to generate extremely stable gold [16] or silver nanoparticles in water [17]. Other process, which was described in the literature, was related to produce silver nanoparticles through oligopeptides catalysis, precipitating the particles with several forms (hexagonal, spherical and triangular) [18]. However, in the fungal reduction of Ag ions led colloidal suspension, differently that in the oligopeptides case. Then the mechanistic aspects are still an open question, however this process occur in the fungal case probably either by reductase action or by electron shuttle quinones or both. Our aims in this research are to compare different strains of $F$. oxysporum in order to understand if the efficiency of the reduction of silver ions is related to a reductase or quinone action.

\section{Results and Discussion}

The Erlenmeyer flasks with the F. oxysporum biomass were a pale yellow color before the addition of $\mathrm{Ag}^{+}$ions and this changed to a brownish color on completion of the reaction with $\mathrm{Ag}^{+}$ions for $28 \mathrm{~h}$. The appearance of a yellowishbrown color in solution containing the biomass suggested the formation of silver nanoparticles [21]. The UV-Vis spectra recorded from the F. oxysporum 07SD strain reaction vessels (Method A) at different times of reaction is presented in Figure 1. The strong surface plasmon resonance centered at ca. 415-420 nm clearly increases in intensity with time. The solution was extremely stable, with no evidence of flocculation of the particles even several weeks after reaction. The inset of Figure 1 shows UV-

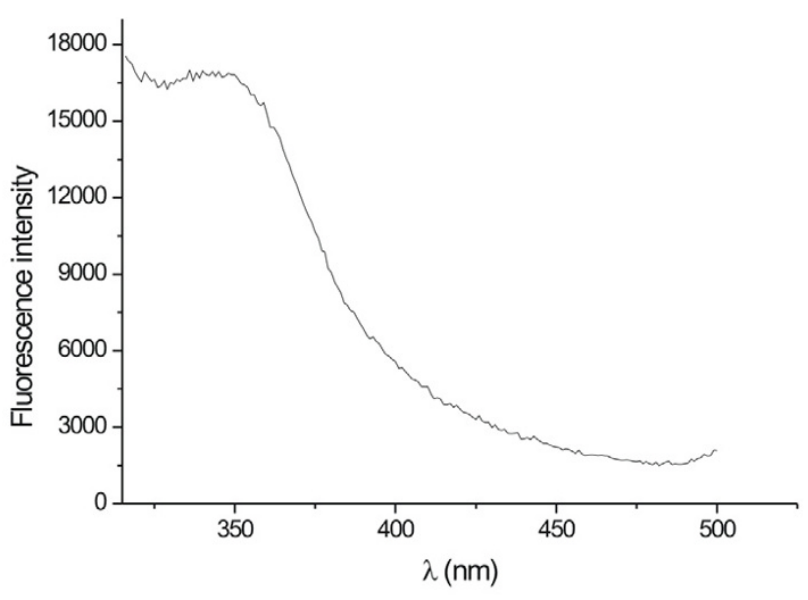

Figure 2

Fluorescence emission spectrum recorded from the silver nanoparticles-fungus reaction mixture. The excitation wavelength was $260 \mathrm{~nm}$.

Vis spectra in low wavelength region recorded from the reaction medium exhibited an absorption band at ca. 265 $\mathrm{nm}$ and it was attributed to aromatic amino acids of proteins. It is well known that the absorption band at ca. 265 $\mathrm{nm}$ arises due to electronic excitations in tryptophan and tyrosine residues in the proteins. This observation indicates the release of proteins into solution by F. oxysporum and suggests a possible mechanism for the reduction of the metal ions present in the solution [17].

Figure 2 shows the fluorescence emission spectra of fungal filtrate of one of the strain (07SD). An emission band centered at $340 \mathrm{~nm}$ was observed. The nature of the emission band indicates that the proteins bound to the nanoparticle surface and those present in the solution exist in the native form [22]. The similar results were observed for all the studied strains as shown in Table 1 . In Table 1, the 07SD strain appeared as the most efficient one in the silver nanoparticles production. Apparently, the different efficiencies are related to the reductase and/or to the quinone generation and will be discussed later. A destabilization of the nanoparticles is evident in the case of $F$. oxysporum 534, 9114 and 91248 strains at 28 hrs, as indicated by a decrease in the $420 \mathrm{~nm}$ absorption.

Similarly, when the biomass was immersed in water and only the fungal filtrate (Method B) was added to a $10^{-3} \mathrm{M}$ $\mathrm{AgNO}_{3}$ solution, the initially colorless aqueous solution changed to a pale yellowish-brown within $28 \mathrm{~h}$ of reaction 


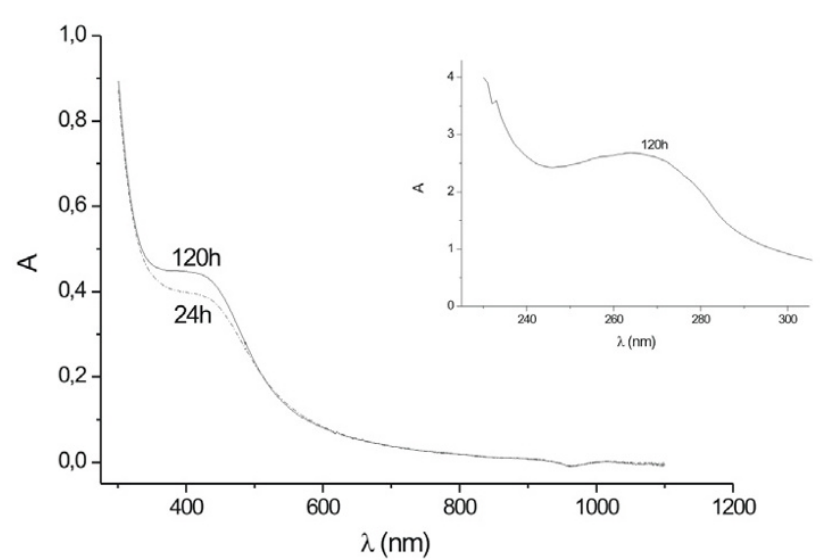

Figure 3

UV-Vis spectra recorded as a function of time of reaction of an aqueous solution of $10^{-3} \mathrm{M} \mathrm{AgNO}_{3}$ with the fungal filtrate (07SD). The inset shows the UV-Vis absorption in the low wavelength region.

(data not shown), clearly indicating that the reduction of the ions occurs extracellularly through reducing agents released into the solution by $F$. oxysporum as it shows the UV-Vis spectra for the 07SD strain (Fig. 3).

Figures 4 and 5 shows the SEM micrograph recorded from the silver nanoparticle (Method A). This picture shows silver nanoparticles aggregates. In this micrograph, spherical nanoparticles in the size range $20-50 \mathrm{~nm}$ were observed. The nanoparticles were not in direct contact even within the aggregates, indicating stabilization of the nanoparticles by a capping agent. This corroborates with the previous observation by Ahmad et al. [17] in their study on F. oxysporum. The same micrograph in the Method $\mathrm{B}$ was observed (not showed). In the analysis by energy dispersive spectroscopy (EDS) of the silver nanoparticles was confirmed the presence of elemental silver signal (Figure $6)$.

The TLC (Cromatography of Thin Layer) analysis on silica gel 60 plates using chloroform-methanol-acetic acid (195:5:1) showed a spot with Rf value of 0.65 , and using benzene-nitromethane-acetic acid (75:25:2) showed a spot with Rf value of 0.85 , corresponding to 2-acetyl-3,8dihydroxy-6-methoxy anthraquinone or its isomers at 2acetyl-2,8-dihydroxy-6-methoxy anthraquinone (Scheme 1 ). This was corroborated by the fluorescence spectrum of the filtrate (Method $\mathrm{A}$ ), which indicates an anthraquinone fluorescence moiety [11]. The excitation spectra at the

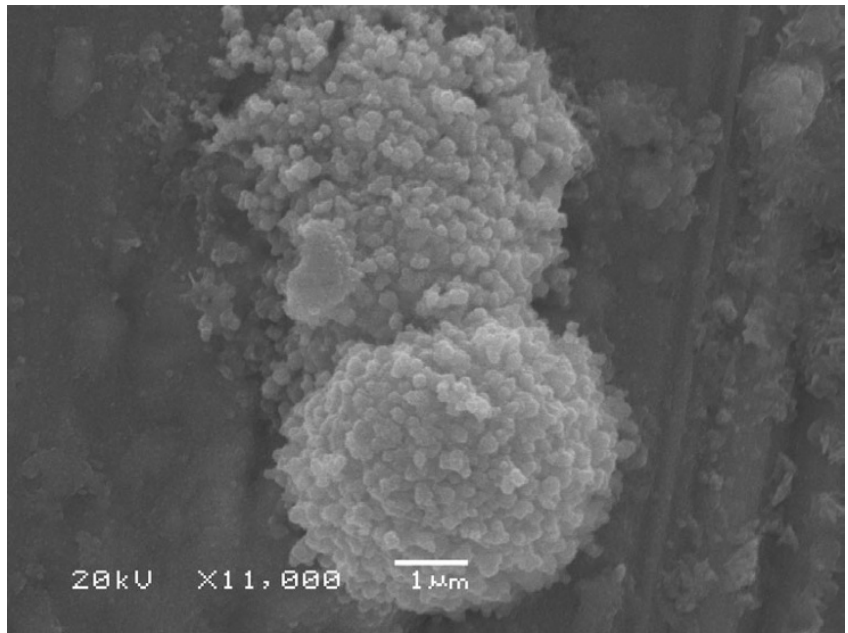

\section{Figure 4}

SEM micrograph from F. oxysporum $07 \mathrm{SD}$ strain at $\times 11000$ magnification.

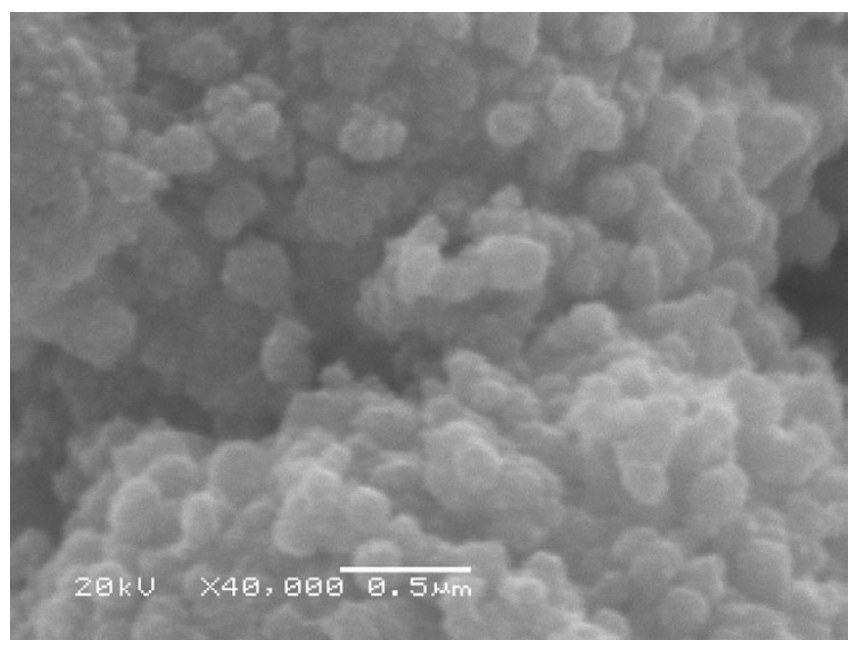

Figure 5

SEM micrograph from F. oxysporum 07 SD strain at $\times 40000$ magnification.

maximum emission $(550 \mathrm{~nm})$ fit quite well with the absorption spectrum of the anthraquinone in Figure 7.

The Figure 8 shows the nitrate reductase through the reaction of nitrite with 2,3-diaminophthalene. The emission spectrum exhibits two major peaks of fluorescence intensity at 405 and $490 \mathrm{~nm}$ corresponding to the emission maximum of the and 2,3-diaminonapthotriazole, DAN (excess) respectively. The intensity of these two bands 


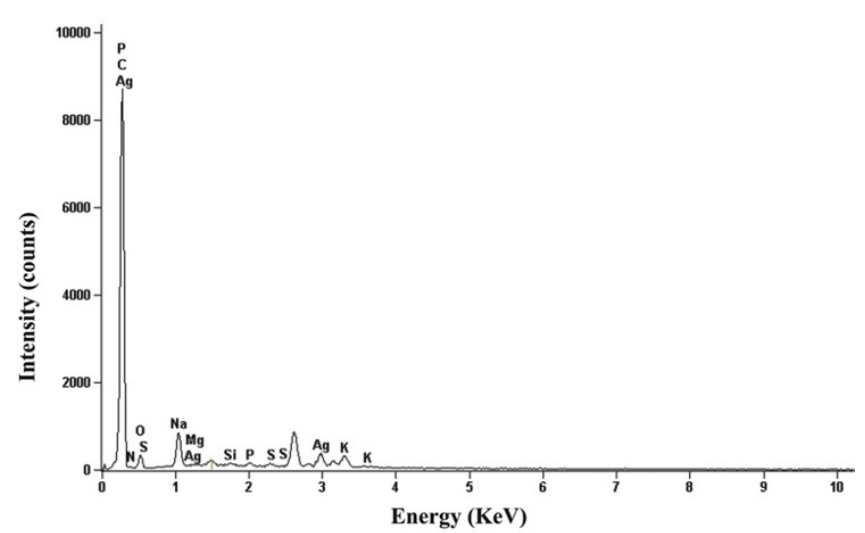

Figure 6

EDS spectra of silver nanoparticles.

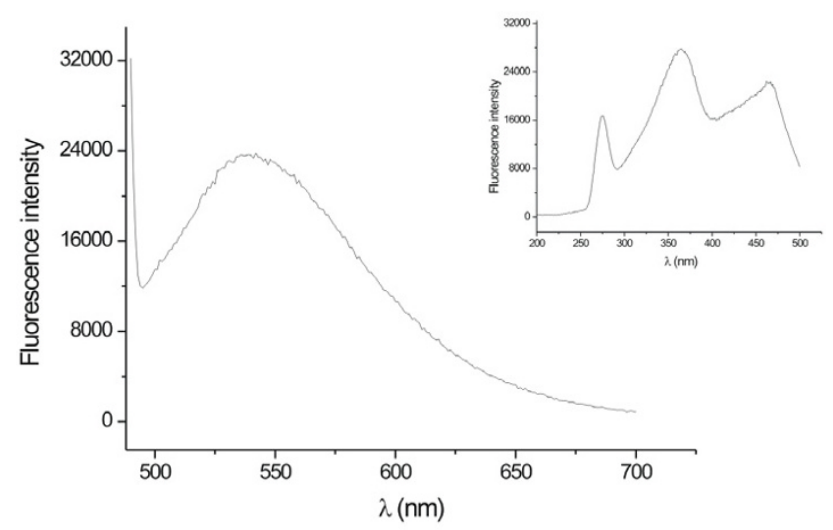

Figure 7

Fluorescence emission spectrum from the aqueous solution of $10^{-3} \mathrm{M} \mathrm{AgNO}_{3}$ with the fungal biomass (07SD). The excitation wavelength was $465 \mathrm{~nm}$. The inset shows the fluorescence excitation spectrum ( $\lambda$ emission at $550 \mathrm{~nm}$ ).

increased with the addition of a $0.1 \% \mathrm{KNO}_{3}$ solution, confirming the presence of nitrate reductase.

It appears that the reductase is responsible for the reduction of $\mathrm{Ag}^{+}$ions and the subsequent formation of silver nanoparticles. The same observation was reported with another strain of F. oxysporum and it was pointed out that this reductase was specific to $F$. oxysporum. However, Fusarium moniliforme, did not result in the formation of silver nanoparticles, neither intracellularly nor extracellularlybut contained intra and extra cellular reductases in a similar fashion as $F$. oxysporum $[17,23]$. This is an indication that probably the reductases in this

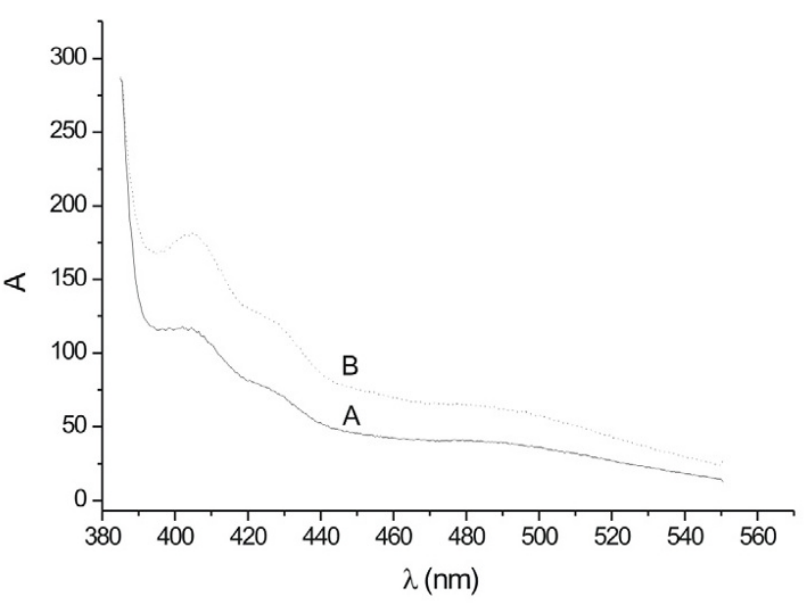

Figure 8

Fluorescence emission spectra for the reaction of nitrite with 2,3-diaminophthalene. In the emission spectra the curves $A$ and $B$ were, respectively: fungal filtrate and fungal filtrate and $0.1 \% \mathrm{KNO}_{3}$ solution. The maximum excitation wavelength was at $375 \mathrm{~nm}$.

kind of Fusarium are important for Fe (III) to Fe (II) but not to $\mathrm{Ag}(\mathrm{I})$ to $\mathrm{Ag}(0)$. Moreover, in F. moniliforme anthraquinones derivatives were not detected unlike the case of F. oxysporum. Both fusarium were alike in the production of naphthaquinones [8] but differed in the production of anthraquinones. Probably, in our case, Ag (0) reduction was mainly due to a conjugation between the electron shuttle with the reductase participation as shown in Figure 9.

\section{Conclusion}

Even though gold/silver nanoparticles have been synthesized using prokaryotes such as bacteria [24,25] and eukaryotes such as fungi $[13,14]$, the nanoparticles grow intracellularly, except in the case of a recent report in which $F$. oxysporum was used. In that case the nanoparticles grew extracellularly [17]. In our case, all the F. oxysporum strains studied exhibited silver nanoparticle production capacity, however, depending on the reductase/electron shuttle relationships under these conditions. Biologically synthesized silver nanoparticles could have many applications, in areas such as non-linear optics, spectrally selective coating for solar energy absorption and intercalation materials for electrical batteries, as optical receptors, catalysis in chemical reactions, biolabelling [26], and as antibacterials capacity [27].

\section{Methods}

The F. oxysporum strains used were the following: $06 \mathrm{SD}$, 07 SD, 534, 9114 and 91248 from ESALQ-USP Genetic 


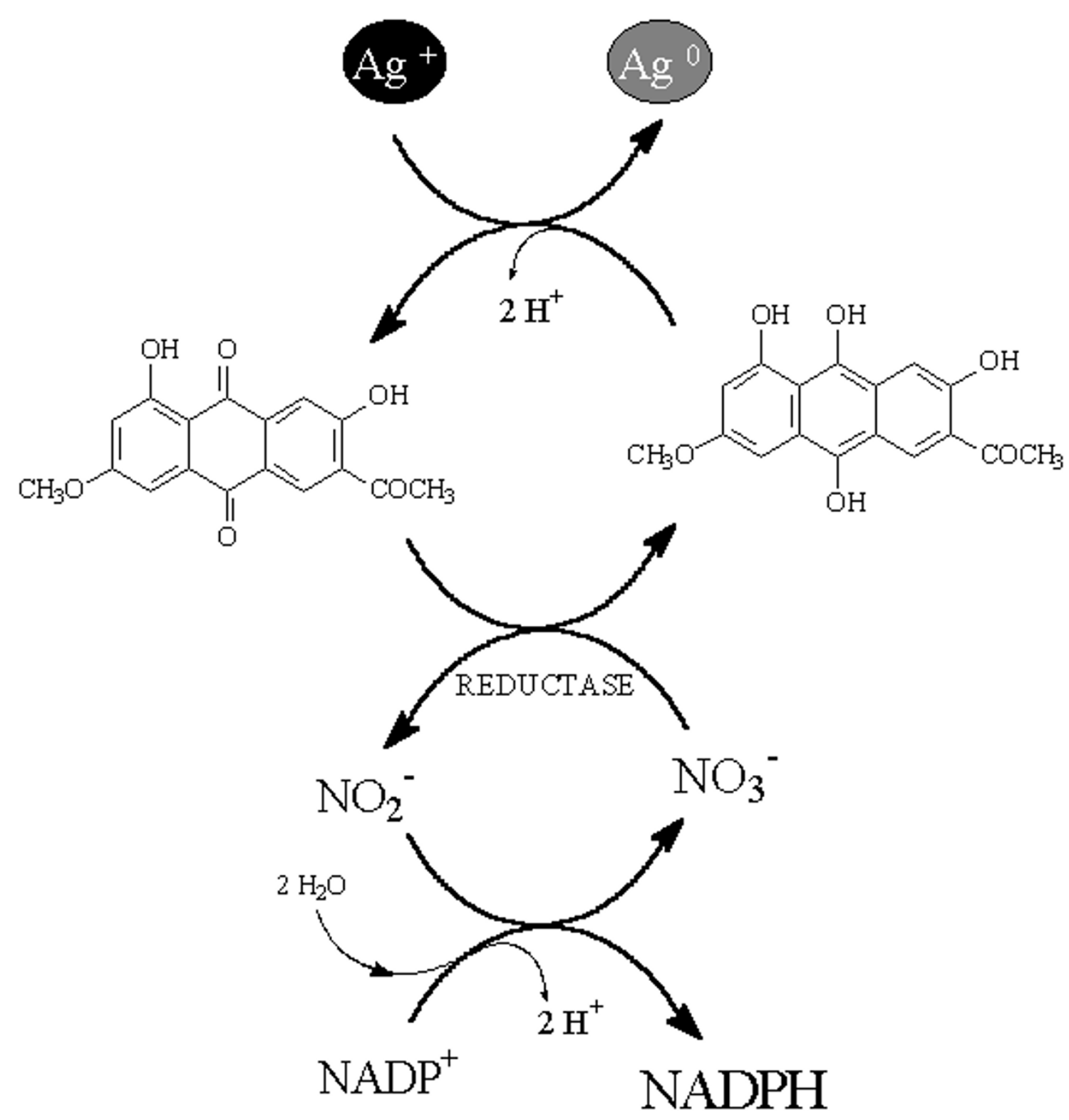

Figure 9

Hypothetical mechanisms of silver nanoparticles biosynthesis.

and Molecular Biology Laboratory-Piracicaba, S.P., Brazil. The fungal inoculates were prepared in a malt extract $2 \%$ and yeast extract $0.5 \%$ at $28^{\circ} \mathrm{C}$ in Petri plates. The liquid fungal growth was carried out in the presence of yeast extract $0.5 \%$ at $28^{\circ} \mathrm{C}$ for 6 days. The biomass was filtrated and resuspended in sterile water. 


\section{Silver reduction and its characterization}

Method A: In the silver reduction, the methodology described previously was followed [17]. Briefly, approximately $10 \mathrm{~g}$ of $F$. oxysporum biomass was taken in a conical flask containing $100 \mathrm{~mL}$ of distilled water. $\mathrm{AgNO}_{3}$ solution $\left(10^{-3} \mathrm{M}\right)$ was added to the erlenmeyer flask and the reaction was carried out in the dark. Periodically, aliquots of the reaction solution were removed and the absorptions were measured using a UV-Vis spectrophotometer (Agilent 8453 - diode array).

Method B: Another test was also carried out as following: approximately $10 \mathrm{~g}$ of $F$. oxysporum biomass was taken in a conical flask containing $100 \mathrm{~mL}$ of distilled water, kept for $72 \mathrm{~h}$ at $28^{\circ} \mathrm{C}$ and then the aqueous solution components were separated by filtration. To this solution, $\mathrm{AgNO}_{3}\left(10^{-3} \mathrm{M}\right)$ was added and kept for several hours at $28^{\circ} \mathrm{C}$.

The silver nanoparticles were characterized by scanning electron microscopy (SEM) and energy-dispersive spectroscopy (EDS) at a voltage of $20 \mathrm{kV}$ (Jeol - JSM$6360 \mathrm{LV}$ ) and previously coated with gold under vacuum.

\section{Determination of the electron-shuttling compounds}

Release of electron-shuttling compounds was followed the methodology described previously [11]: In order to determine the water-soluble quinones that might function as an electron shuttle, cultures were filtered 4-6 weeks, and the filtrate adjusted to $\mathrm{pH} 3$ with $\mathrm{HCl} 1 \mathrm{M}$. The acidified solution was then passed through a column with ion exchange resin (Amberlite ${ }^{\circledR}$ ) for absorption of the pigments. Compounds were removed from the column by elution with acetone, the acetone removed using a Buchi rotary evaporation and the aqueous phase extracted 3 times with ethyl acetate. All ethyl acetate extractions were combined and reduced using the rotary evaporator. After that, $2 \mu \mathrm{L}$ samples were repeatedly spotted on a Silica gel 60 plate until a spot was visible under UV light at $254 \mathrm{~nm}$. Samples were resolved using a chloroform-methanol-acetic acid (195:5:1) and benzene-nitromethane-acetic acid (75:25:2) system designed to mobilize polar pigments. Plates were air dried, and spots visualized under UV light [19].

\section{Nitrate reductase assay}

Nitrate reduction was demonstrated in the same medium (Method A and B) of the same growth broth of F. oxysporum with the addition of $0.1 \%$ of $\mathrm{KNO}_{3}$ [6]. The nitrate reductase test was made after 2 days by fluorometric method [20]. Briefly, $100 \mu \mathrm{L}$ fungal filtrate and $200 \mu \mathrm{L}$ of dionized water. To this, $10 \mu \mathrm{L}$ of freshly prepared 2,3diaminonaphtalene (DAN) $(0.05 \mathrm{mg} / \mathrm{mL}$ in $1 \mathrm{M} \mathrm{HCl})$ is added and mixed immediately. After $10 \mathrm{~min}$ incubation at $20^{\circ} \mathrm{C}$, the reaction was stopped with $5 \mu \mathrm{L}$ of $0.1 \mathrm{M} \mathrm{NaOH}$.
The intensity of the fluorescent signal produced by the product was maximized by the addition of base. The 2,3diaminonapthotriazole formation was measured using a Perkin-Elmer (LS-55) luminescence spectrophotometer with and excitation wavelength at $375 \mathrm{~nm}$ and the emission band measured at $550 \mathrm{~nm}$ [20].

\section{Determination of the tryptophan/tyrosine residues}

Presence of tryptophan/tyrosine residues in proteins release in the fungal filtrated was analyzed by fluorescence [17]. The fluorescence measurements were carried out on a Perkin-Elmer (LS-55) luminescence spectrophotometer. The exitation wavelength was $260 \mathrm{~nm}$, close to maximal optical transitions of the tryptophan and tyrosine.

\section{Authors' contributions}

ND conceived the study, together with OLA and EE and participated in its design and coordination and collected all the data and wrote the paper. PDM obtained all the SEM views, performed the enzymatic assays, the electron shuttling aspects and discussed the three related parts in the manuscript. GIHS performed all the fungal tests and measured all the spectroscopic variations of the plasmon resonance of the silver nanoparticles supervised by EE. OLA also supervised all the nanoparticles aspects in this work. All authors read and approved the final manuscript.

\section{Acknowledgements}

Supports from Brazilian Network of Nanobiotechnology, CNPq/MCT and FAPESP are acknowledged. We acknowledge Dr. Fernando de Oliveira from NCA-UMC for the UV-Vis analyses support.

\section{References}

I. Schroder I, Johnson E, De Vries S: Microbial ferric iron reductases. FEMS Microbiol Rev 2003, 27:427-447.

2. Homuth $M$, Valentin-Weiganz P, Rohde M, Gerlach GF: Identification and characterization of a novel extracellular ferric reductase from Mycobacterium paratuberculosis. Infect Immun 1998, 66:710-716.

3. Newman DK, Kolter R: A role for excreted quinones in extracellular electron transfer. Nature 2000, 405:94-97.

4. Hernandez ME, Newman DK: Extracellular electron transfer. Cell Mol Life Sci 200I, 56:I562-I57I.

5. Gunner HB, Alexander M: Anaerobic growth of Fusarium oxysporum. J Bacteriol 1964, 87:1309-1316.

6. Ottow JCG, Von Klopotek A: Enzymatic reduction of iron oxide by fungi. Appl Microbiol 1969, I 8:41-43.

7. Lloyd JR: Microbial reduction of metals and radionuclides. FEMS Microbiol Rev 2003, 27:4 I I-425.

8. Medentsev AG, Alimenko VK: Naphthoquinone metabolites of the fungi. Phytochemistry 1998, 47:935-959.

9. Duran N, Teixeira MFS, De Conti R, Esposito E: Ecological-friendly pigments from fungi. Crit Rev Food Sci Nutr 2002, 42:53-66.

10. Bell AA, Wheeler MH, Liu J, Stipanovic RD, Puckhaber LS, Orta H: United States Department of Agriculture-Agricultural Research Service studies on polyketide toxins of Fusarium oxysporum $f$ sp vasinfectum: potential targets for disease control. Pest Manag Sci 2003, 59:736-747.

II. Baker RA, Tatum JH: Novel anthraquinones from stationary cultures of Fusarium oxysporum. J Ferment Bioeng 1998, 85:359-36I.

12. Fortin D, Beveridge TJ: Mechanistic routes towards biomineral surface development. In Biomineralisation Edited by: E Baeuerlein. 
Biology to Biotechnology and Medical Application, Wiley-VCH, Verlag, Germany; 2000:294.

13. Mukherjee P, Ahmad A, Mandal D, Senapati S, Sainkar SR, Khan MI, Ramani R, Parischa R, Ajaykumar PV, Alam M, Sastry M, Kumar R: Bioreduction of $\mathrm{AuCl}^{4-}$ ions by the fungus, Verticillium sp. and surface trapping of the gold nanoparticles formed. Angew Chem Int Ed 200I, 40:3585-3588.

14. Mukherjee P, Ahmad A, Mandal D, Senapati S, Sainkar SR, Khan MI, Parischa R, Ajayakumar PV, Alam M, Kumar R, Sastry M: Fungusmediated synthesis of silver nanoparticles and their immobilization in the mycelial matrix: A novel biological approach to nanoparticle synthesis. Nano Lett 200I, I:5 I5-5I9.

15. Sastry M, Ahmad A, Islam NI, Kumar R: Biosynthesis of metal nanoparticles using fungi and actinomycete. Current Sci 2003, 85:162-170.

16. Mukherjee P, Senapati S, Mandal D, Ahmad A, Khan MI, Kumar R, Sastry M: Extracellular synthesis of gold nanoparticles by the fungus Fusarium oxysporum. Chem Biochem 2002, 3:46I-463.

17. Ahmad A, Mukherjee P, Senapati S, Mandal D, Khan MI, Kumar R, Sastry M: Extracellular biosynthesis of silver nanoparticles using the fungus Fusarium oxysporum. Colloids Surf B 2003, 28:3।3-3I8.

18. Naik RR, Stringer SJ, Agarwal G, Jones SE, Stone MO: Biomimetic synthesis and patterning of silver nanoparticles. Nat Mater 2002, I:169-172.

19. Nevin KP, Lovley DR: Mechanisms for accessing insoluble Fe (III) oxide during dissimilatory Fe (III) reduction by Geothrix fermentans. Appl Environm Microbiol 2002, 68:2294-2299.

20. Misko TP, Schilling RJ, Salvemini D, Moore WM, Currie MG: A Fluorometric assay for the measurement of nitrite in biological samples. Anal Biochem 1993, 214:1 I-16.

2I. Sastry M, Patil V, Sainkar SR: Electrostatically controlled diffusion of carboxylic acid derivatized silver colloidal particles in thermally evaporated fatty amine films. J Phys Chem B 1998, 102:1404-1410.

22. Kumar CV, McLendon GL: Nanoencapsulation of cytochrome $\mathbf{c}$ and horseradish peroxidase at the galleries of alpha-zirconium phosphate. Chem Mater 1997, 9:863-870.

23. Klittich CJR, Leslie JF: Nitrate reduction mutants of Fusariummoniliforme (gibberella-fujikuroi). Genetics 1988, I | 8:4 |7-423.

24. Joerger R, Klaus T, Granqvist CG: Biologically produced silvercarbon composite materials for optically functional thin-film coatings. Adv Mater 2000, I 2:407-409.

25. Klaus-Joerger T, Joerger R, Olsson E, Granqvist CG: Bacteria as workers in the living factory: metal-accumulating bacteria and their potential for materials science. Trends Biotechnol 200I, 19:15-20.

26. Kowshik M, Ashtaputre S, Kharrazi S, Vogel W, Urban J, Kulkarni SK, Paknikar KM: Extracellular synthesis of silver nanoparticles by a silver-tolerant yeast strain MKY3. Nanotechnology 2003, 14:95-100

27. Souza GIH, Marcato PD, Durán N, Esposito E: Utilization of Fusarium oxysporum in the biosynthesis of silver nanoparticles and its antibacterial activities. In IX National Meeting of Environmental Microbiology Curtiba, PR (Brazil); 2004. Abstract pag. 25

\section{Publish with Bio Med Central and every scientist can read your work free of charge}

"BioMed Central will be the most significant development for disseminating the results of biomedical research in our lifetime. "

Sir Paul Nurse, Cancer Research UK

Your research papers will be:

- available free of charge to the entire biomedical community

- peer reviewed and published immediately upon acceptance

- cited in PubMed and archived on PubMed Central

- yours - you keep the copyright
Biomedcentral 